\title{
Cranial Bone Flap Fixation: Comparison of Titanium-Based Device (Skull Fix) and PEEK-Based Device (Cranial Loop): Technical Report
}

\author{
ISLAM ABOULFETOUH, M.D. and WALID A. YOUNES, M.D. \\ The Department of Neurosurgery, Faculty of Medicine, Banha University
}

\begin{abstract}
Background: Reconstruction of the cranial bone flap after craniocerebral surgery is crucial for preservation of skull symmetry, maintenance of aesthetics, brain protection, as well avoiding complications like floating or sunken skull flaps. A host of techniques and materials for fixation of the cranial flaps have emerged over the past several decades.
\end{abstract}

Aim of Study: The aim of this study was to compare the clinical outcomes of bone flap fixation using peek-based (cranial loop) versus titanium-based (skull fix) fixation systems.

Patients and Methods: Between July 2013 and December 2016 a series of 54 patients undergoing either an emergency or an elective craniotomy for different intracranial lesions in which the original bone flaps were refixed using cranial loop in 27 patients and skull fix in 27 patients. Clinical and radiological outcomes and complication rates were compared between these 2 groups.

Results: Satisfactory results were achieved in both fixation systems. Epidural collection occurred in 4 patients 3 in skull fix and one in cranial loop, subdural collection in 4 patients 2 in cranial loop and one in skull fix treated conservatively. One case with cranial loop experienced a bone flap dislocation which was revised and refixed. Subcutaneous effusion occurred in two patients one in skull fix and one in cranial loop. One patient in skull fix developed a mild postoperative wound infection. Post-operative imaging showed satisfactory anatomical and morphological position of the flap in all patients.

Conclusion: Skull fix and cranial loop are reasonable alternatives to present craniotomy fixation methods. They are easy to use, fast, safe, reliable with very acceptable cosmetic results. The main advantage of the cranial loop might ultimately lie in the absence of artifacts on post-operative CT or MR imaging.

Key Words: Craniotomy - Cranial bone fixation - Cranial loop - Skull fix.

\section{Introduction}

REALIGNMENT and fixation of skull bones following intracranial surgeries or skull fractures

Correspondence to: Dr. Islam Aboulfetouh, E-Mail: islamfetoh@hotmail.com is an important issue for both neurosurgeons and patients [1].

A fixation device must therefore secure the cranial flap to protect the delicate brain, to obtain acceptable cosmetic appearance and to avoid complication or reoperation $[2,3]$.

The techniques and materials of fixating a bone flap have evolved over time. Its evolution has been guided by technology, including surgical instrument development, anatomy and concerns about cosmosis and infection prevention. Multiple traditional in addition to newer techniques are available, each with pros and cons $[4,5]$.

Bone flaps have been tied in place with sutures (silk, cotton, or chromic catgut) [6,7]. Wire (silver or stainless) $[\mathbf{8 , 9 ]}$, fixating metal pins [10], metal plates and screws (stainless steel, tantalum, titanium) and more recently Biodegradable and PEEKbased cranial fixation systems [11-14].

The purpose of this study was to describe the characteristics and possible complications of titanium clamp fixation system (Skull Fix; BMI Medical-Welling Instruments Co. USA-Taiwan Joint Venture Co.) and PEEK-based cranial fixation system (Cranial Loop, Neos Surgery, Spain).

\section{Patients and Methods}

This retrospectives study done in governmental hospitals in Saudia Arabia between July 2013 and December 2016 where the medical records of a series of 54 patients undergoing either an emergency or an elective craniotomy for different intracranial lesions in which the original bone flaps were refixed using cranial loop in 27 (14 male and 13 females) and patients and skull fix in 27 (15 male, 12 female) patients. Each patient was partially shaved and received perioperative antibiotics. 
For those patients where skull fix was used we use 3 clamps for each patient ( 4 clamps were used in 2 patients with larger bone flap and 2 clamps in 1 patient with smaller bone flap) the clamp system used in our cases consists of two concave discs, each with a diameter of $18 \mathrm{~mm}$ and a thickness of $0.3 \mathrm{~mm}$, mounted on a $50-\mathrm{mm}$-long, $1-\mathrm{mm}$-thick pin with circumferential grooves. The clamps were positioned along the circumference of the cranial flap with the inner disc placed partly in the epidural space under the bone edge, the clamps were held by hand as the free craniotomy flap was lowered into position the outer disc then sequentially squeezed and advanced over the threaded pin down toward the outer table, the excess pin projecting above the outer disc was snipped off with the pin cutter Fig. (1).

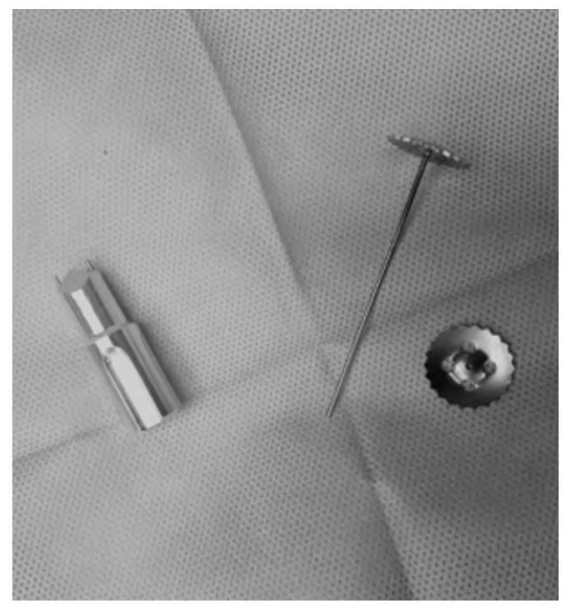

(A)

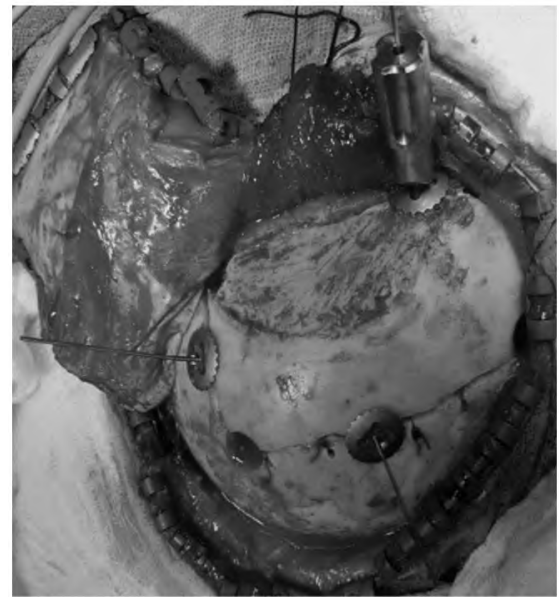

(C)
For those patient who underwent cranial bone flap fixation with cranial loop 3 loops (4 clamps were used in 5 patients with larger bone flap) were placed in situ, in all patients, the bone flap could be easily fixed with 3 or more cranial loops without difficulties the bone flap was positioned in the craniotomy opening and the cranial loops were tightened one by one till the bone flap was firmly fixed. Subsequently the cranial loops were cut and the yellow appliers are slid off. By bending the remaining Loops a few times they break just at the fixation point without having a sharp point Fig. (2).

Comments regarding the time taken, the number of clamps/loops, the stability of bone flaps and faced problems were recorded. Follow-up charts and files regarding clinical and radiological data were also recorded and evaluated.

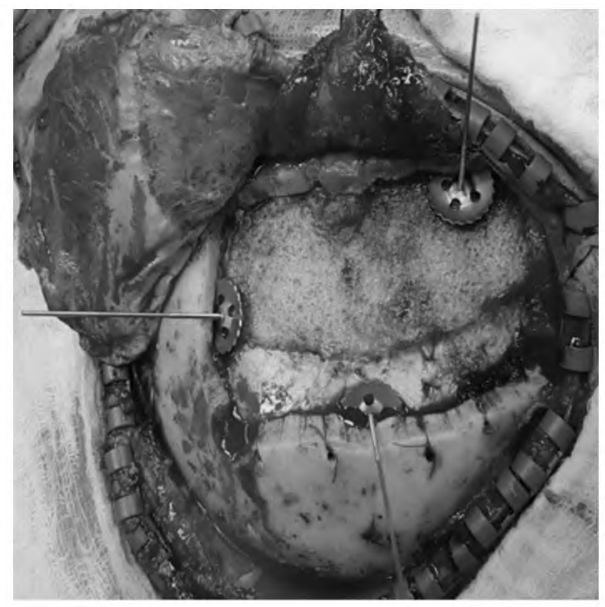

(B)

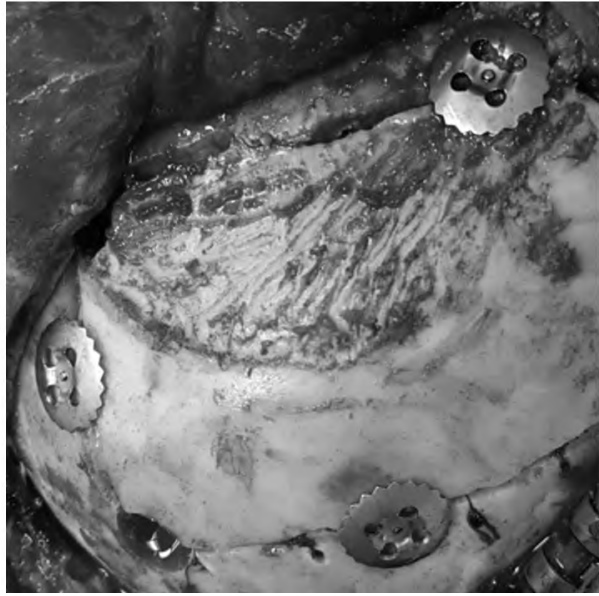

(D)

Fig. (1): (A) The titanium clamp Skull fix. (B) The inner disc placed partly in the epidural space under the bone edge. (C) Bone flap reattached and Insertion of the outer disc with the wrench on top turned clockwise to secure it (D) Final position. 


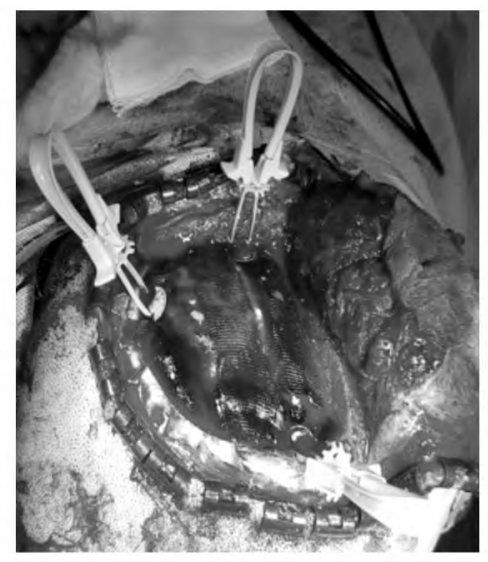

(A)

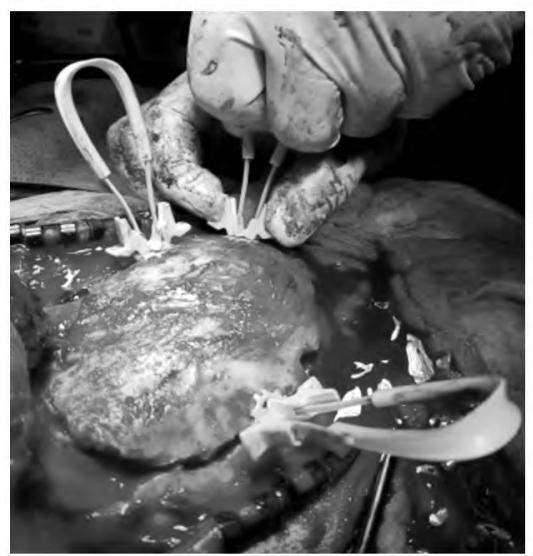

(C)

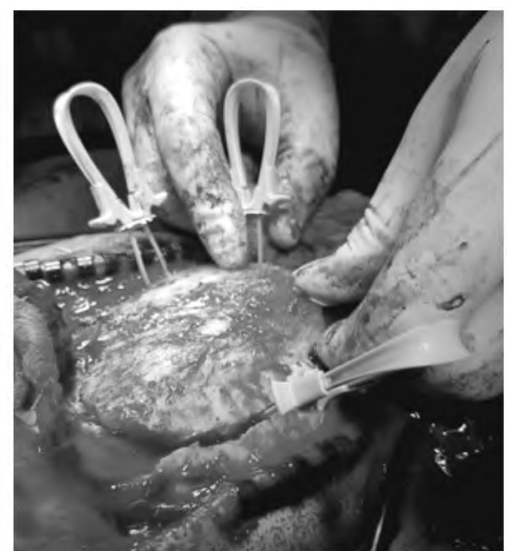

(B)

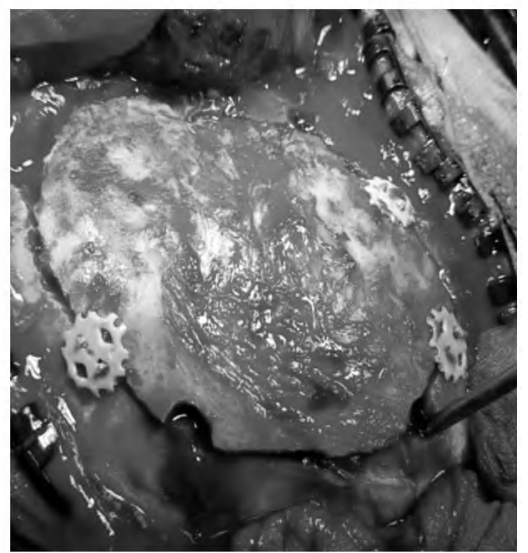

(D)

Fig. (2): Application of the cranial loop. (A) Insertion of the cranial loops at the bone edges, between the dura and the bone. (B) Putting back the bone flap and tightening of the cranial loop. (C) Breaking the strips of the loop at the fixation point without leaving a sharp point. (D) Final result.

\section{Results}

54 patients were operated where cranial flap was fixed using skull fix in 27 patients and cranial loop in 27 patients. All operative procedures passed uneventful. It was fast, easy without technical difficulties. Each bone flap was firmly fixed using 3 or more devices in not more than 1 minute for every device. In both devices there was excellent adaptation either at the epidural or the extracranial surface. No encountered intraoperative dural or scalp injuries or intracranial hemorrhage. Only one case of post-operative wound infection was recorded in skull fix group and was treated conservatively. Reoperation was done in only one patient who experienced bone flap dislocation that was attributed to inadequate number of cranial loops in relation a large sized bone flap. Subcutaneous effusion occurred in two patients (one for each group) and subsides spontaneously. Epidural collection occurred in 4 patients ( 3 patients in skull fix group and 1 patient in cranial loop group) all treated conservatively. Subdural collection in 4 patients ( 2 patients in skull fix group and 2 patients in cranial loop group) all treated conservatively. All patients were satisfied about the cosmetic result of the wound. Apart from the patient with bone flap dislocation; post-operative 3D CT imaging showed satisfactory anatomical and morphological position of the flap in all patients. Post-operative MRI brain showed satisfactory results with minor artifact in the skull fix group Fig. (3) in contrast to the cranial loop group that was completely artifact free Fig. (4).

Patient characteristics are summarized in (Tables $1,2)$. 
Fig. (3): Post-operative imaging of patient after skull fix implantation. (A) 3D CT showed good anatomical position of the bone flap. (B) MRI brain with noticed minor artifact
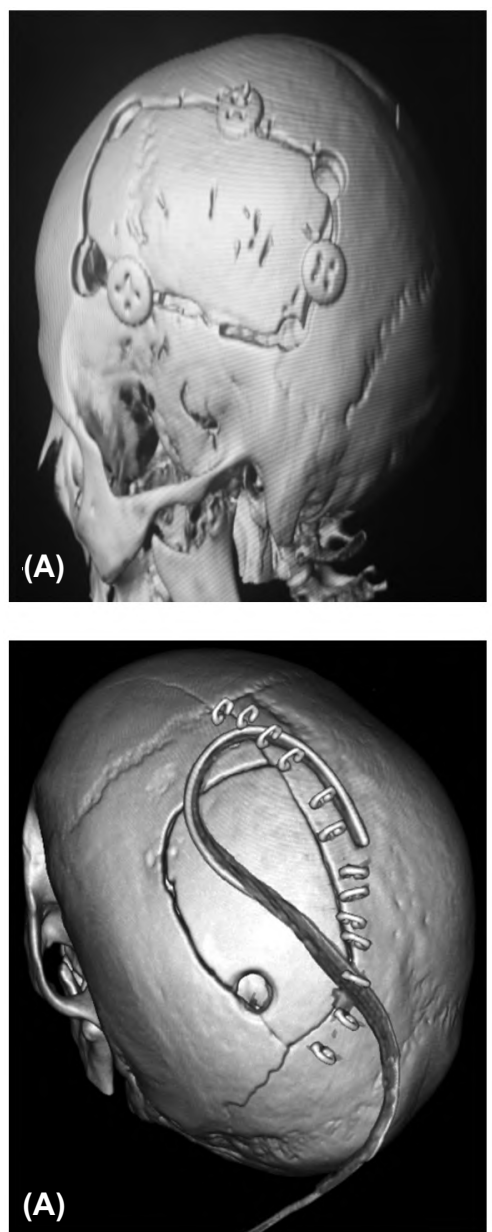
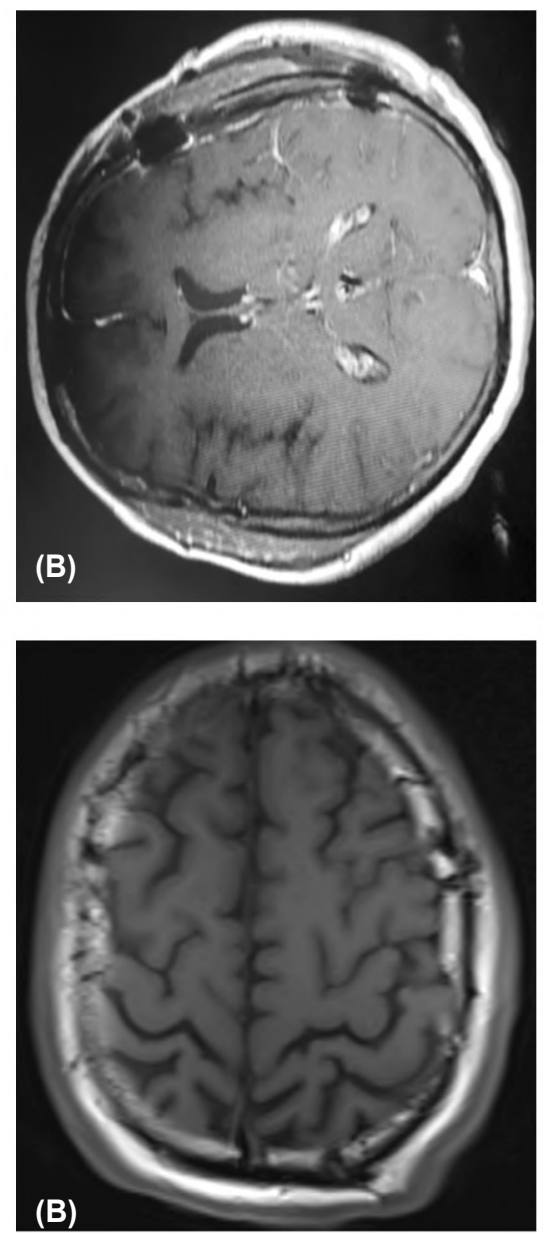

B)

Fig. (4): Post-operative imaging of patient after cranial loop implantation. (A) 3D CT showed good anatomical position of the bone flap. (B) MRI brain without artifact.

Table (1): Results in the skull fix group.

\begin{tabular}{|c|c|c|c|c|c|c|c|}
\hline Number & Age & Sex & Diagnosis & Approach & $\begin{array}{l}\text { Number } \\
\text { of clamps }\end{array}$ & $\begin{array}{l}\text { Post op } \\
\text { CT }\end{array}$ & Post op complications \\
\hline 1 & 18 & Male & Acute subdural hematoma & $\begin{array}{l}\text { - Cranioplasty following } \\
\text { decompressive craniotomy }\end{array}$ & 3 & In place & - \\
\hline 2 & 57 & Male & Glioma & - Parietal & 3 & In place & Minimal extradural collection \\
\hline 3 & 63 & Female & MCA infarction & $\begin{array}{l}\text { - Cranioplasty following } \\
\text { decompressive craniotomy }\end{array}$ & 3 & In place & \\
\hline 4 & 53 & Male & Meningioma & - Parasaggital & 3 & In place & \\
\hline 5 & 45 & Female & Metastases & - Frontal & 3 & In place & - \\
\hline 6 & 24 & Male & Brain abscess & - Frontal & 3 & In place & Wound infection \\
\hline 7 & 67 & Female & Intracerebral hematoma & - Parietal & 3 & In place & \\
\hline 8 & 43 & Male & Glioma & - Frontoparietal & 3 & In place & - \\
\hline 9 & 32 & Male & Extradural Hematoma & - Frontal & 3 & In place & - \\
\hline 10 & 44 & Male & Glioma & • Frontotemporal & 3 & In place & - \\
\hline 11 & 63 & Female & MCA infarction & $\begin{array}{l}\text { - Cranioplasty following } \\
\text { decompressive craniotomy }\end{array}$ & 3 & In place & Minimal subdural collection \\
\hline 12 & 20 & Male & Extradural hematoma & - Temporal & 3 & In place & - \\
\hline 13 & 70 & Female & Intracerebral hematoma & - Occipital & 3 & In place & - \\
\hline 14 & 57 & Male & Meningoma & - Parasagittal & 3 & In place & - \\
\hline 15 & 36 & Female & Traumatic CSF leak & - Bifrontal & 4 & In place & Minimal extradural collection \\
\hline 16 & 43 & Male & Acute subdural hematoma & - Frontoparietal & 3 & In place & \\
\hline 17 & 41 & Female & Brain abscess & - Temporal & 3 & In place & - \\
\hline 18 & 46 & Female & Meningioma & - Parietal & 3 & In place & - \\
\hline 19 & 36 & Female & Metastases & - Occipital & 3 & In place & - \\
\hline 20 & 59 & Male & Glioma & - Temporal & 3 & In place & \\
\hline 21 & 39 & Male & Depressed skull fracture & - Parietal & 3 & In place & Subcutaneous effusion \\
\hline 22 & 66 & Female & Metastases & - Frontal & 2 & In place & \\
\hline 23 & 48 & Female & Intracerebral hematoma & - Frontotemporal & 3 & In place & - \\
\hline 24 & 43 & Male & Extradural $\mathrm{h}$ & - Frontal & 3 & In place & Minimal subdural collection \\
\hline 25 & 18 & Male & Acute subdural hematoma & - Frontoparietal & 4 & In place & \\
\hline 26 & 39 & Male & Depressed skull fracture & - Temporal & 3 & In place & - \\
\hline 27 & 65 & Female & Intracerebral hematoma & - Frontoparietal & 3 & In place & Minimal extradural collection \\
\hline
\end{tabular}


Table (2): Results in the cranial loop group.

\begin{tabular}{|c|c|c|c|c|c|c|c|}
\hline Number & Age & Sex & Diagnosis & Approach & $\begin{array}{l}\text { Number } \\
\text { of loop }\end{array}$ & Post op CT & Post op complications \\
\hline 1 & 46 & Female & Acute subdural & Frontoparietal & 3 & In place & - \\
\hline 2 & 57 & Female & Meningioma & Temporal & 3 & In place & - \\
\hline 3 & 63 & Female & Meningima & Bifrontal & 4 & In place & \\
\hline 4 & 67 & Male & Brain abcess & Parietooccipital & 3 & Dislodged bone flap & Dislodged bone flap \\
\hline 5 & 47 & Female & Glioma & Frotopaietal & 4 & In place & - \\
\hline 6 & 56 & Male & Meningioma & Frontal & 3 & In place & - \\
\hline 7 & 37 & Male & Glioma & Fronto Temporal & 4 & In place & Minimal epidural collection \\
\hline 8 & 39 & Male & Metastases & Pterional & 3 & In place & - \\
\hline 9 & 42 & & Extradural hematoma & Pterional & 3 & In place & - \\
\hline 10 & & Female & Glioma & Frontoparietal & 3 & In place & - \\
\hline 11 & 63 & Male & Glioma & Occipital & 3 & In place & Minimal subdural collection \\
\hline 12 & 42 & & Extradural hematoma & Temporal & 3 & In place & \\
\hline 13 & 55 & Female & Intracerebral hematoma & Pterional & 3 & In place & - \\
\hline 14 & 61 & Male & Meningoma & Frontal & 3 & In place & - \\
\hline 15 & 39 & Female & Glioma & Temporoparietal & 4 & In place & - \\
\hline 16 & 53 & Male & Meningioma & Pterional & 3 & In place & - \\
\hline 17 & 41 & Female & Glioma & Frontal & 3 & In place & \\
\hline 18 & 43 & Male & Extradural & Pterional & 3 & In place & - \\
\hline 19 & 26 & Male & Metastases & Temporal & 3 & In place & - \\
\hline 20 & 59 & Female & Glioma & Occipital & 3 & In place & \\
\hline 21 & 27 & Male & Acute subdural & Temporoparietal & 3 & In place & \\
\hline 22 & 43 & Female & Meningioma & Pterional & 3 & In place & \\
\hline 23 & 62 & Male & Metastases & Frontal & & In place & Subcutaneous effusion \\
\hline 24 & 33 & Female & Glioma & Fronttemporal & 3 & In place & - \\
\hline 25 & 23 & Female & Extradural h & Petrional & 3 & In place & Minimal sudural collection \\
\hline 26 & 61 & Female & Acute subdiral & Temporoparietal & 4 & In place & - \\
\hline 27 & 38 & Male & Extradural hematoma & Temporal & 3 & In place & - \\
\hline
\end{tabular}

\section{Discussion}

Bone flap fixation after craniotomy is a standard part of neurosurgical practice.

Believing that a preserved vascular supply to the bone fragment would reduce the risk of infection, Wagner recommended the preservation of a connecting hinge of overlying soft tissue, in the form of pericranium or temporalis muscle, "turning a Wagner flap" [15].

Historically, bone flap fixation was performed with steel wire which was somewhat complicated; the scalp may be punctured by the wire end in some cases [8]. And it showed extensive metal artifacts on CT imaging [10].

Sutures are cheap and do not require special equipment or tools [4] but it is time-consuming, carries a higher risk of damaging the dura and the brain during bone perforation [10,11], and could not provide a stable attachment of the bone flap leading to either bone flap settling or dislocation (frequently resulting in depression or protrusion) $[\mathbf{1 1 , 1 6}]$

Artificial fixation systems have been used to secure cranial bone flaps since the 1990s. They are easily manipulated, provide superior rigid fixation, promote primary bone healing, produce a superior cosmetic result, and are CT and MRI compatible.
They may even be useful in infected bone flap fixation $[5,8,17,18]$.

The skull fix titanium clamp system is a titanium-based fixation system which consists of two titanium smooth-surfaced discs attached to a pin [3,14]. While cranial LOOP is the first-ever cranial fixation device totally made of PEEK which is broadly accepted as a leading high performance candidate for replacing metal implants [19] .

The titanium discs act as a clamp across the cut edge of both the skull and the bone flap [14,20,21] Sandwiching the cranial flap margins for a better purchase against the bone surface, with the edges of cranial flap matching the edges of skull defect exactly producing an excellent cosmetic result $[3,14]$.

The shape and flexibility of the cranial loop adjusts to the curvature and shape of the cranium, thus improving security of the device, guaranteeing the minimal possible profile at both the epidural and epicranial surfaces of the skull creating an overall smooth, adapted structure and satisfactory cosmetic results [13]

In our study, post-operative follow-up showed satisfactory results on close inspection or palpation where there were no esthetically objectionable 
bulges, areas of tenderness, skin abnormalities or palpable devices.

We found skull fix easy to use, fast and nontime consuming ( 3 minutes for 3 point fixation system) and this was comparable to other studies $[3,14]$.

Cranial LOOP is implanted with no additional instruments. Its unique design makes it a selfcutting device. The surgeon totally controls the bone flap fixation. The principle of cranial loops is the same as that of a cable tie with a simple fast and easy "pull-and-tighten" action. If a reoperation is necessary, the device is easily removed by using a rongeur [13].

In our study using three Cranial LOOPs, a standard bone flap is fixed in less than 3 minute and this was in agreement of other studies.

Skull fix enjoys a characteristics tensile strength leading to a reliable rigid fixation with a good spring elastic-reserve. During follow up period we had no bone flap deformity (either depression or protrusion). These data was in agreement of previous studies [3,8,14,20,21].

Cranial loop has a unique design which guarantees the same fixation strength as titanium plates and screws, or other standard metallic noninstrument-free cranial fixation devices [22].

Apart from one case we had no evidence of cranial flap settling or dislocation either clinically or on the post-operative images which revealed a good anatomic position for all patients except for one case which needs revision because of dislodged flap due to inadequate number of loops for the large sized flap.

Skull fix is CT and MRI compatible with minor artifact related to its metallic component. Experiments in a $1.5 \mathrm{~T}$ MR tomograph with titanium clamps revealed no magnetic field attraction, minimal heating, and minor artifactual signal void [23] We noticed this artifact but it does not interfere with proper postoperative radiological evaluation.

On the other side cranial loop is completely artifact-free in different medical imaging systems, such as X-rays, CT scanning and MRI [19]. In our study the total absence of artifacts on post-operative MR or CT imaging is favorable in patients who require post-operative follow-up imaging and this is going with other study by Van Loock et al., [13]

Skull fix proved high safety margin with no device related complications e.g dural injury, in- fection or skin erosion), again the cranial loop had a high safety margin since the pulling force is away from the dura and this implies no risk for damaging the dura or other intracranial tissues.

In our study we use 3 devices of both types for each craniotomy bone flap. More than 3 devices was only indicated in multi-fragmented bone flap pieces such as in trauma patients or in larger flaps $[13,21]$. For small bone flaps, the use of 2 devices is sufficient to provide optimal alignment of the bone flap and to provide firm fixation [13,21]

\section{Conclusion:}

Skull fix and cranial loop are reasonable alternatives to present craniotomy fixation methods. They are easy to use, fast, safe, reliable with very acceptable cosmetic results. The main advantage of the cranial loop might ultimately lie in the absence of artifacts on post-operative CT or MR imaging. Further experience may be necessary to elucidate the benefits that support their widespread use.

\section{References}

1- FRATI A., PICHIERRI A., ESPOSITO V., FRATI R., DELFINI R., CANTORE G., BASTIANELLO S. and SANTORO A.: Aesthetic issues in neurosurgery: A protocol to improve cosmetic outcome in cranial surgery. Neurosurg. Rev., 30 (1): 69-77, 2007.

2- WANG Y.R., SU Z.P., YANG S.X., GUO B.Y. and ZENG Y.J.: Biomechanical evaluation of cranial flap fixation techniques: Comparative experimental study of suture, stainless steel wire, and rivetlike titanium clamp. Ann. Plast. Surg., 58 (4): 388-91, 2007.

3- SHU-XU, YANG, et al.: A study of fractured cranial flap refixation Journal of Plastic, Reconstructive \& Aesthetic Surgery, 62 (11): 1424-1442, 2009.

4- SINGH N. and STEINBOK P.: Craniotomy bone flap fixation: Revisiting the use of bone struts. Childs Nerv Syst., 34: 1235-9 https://doi.org/10.1007/s00381-0173620-x, 2018

5- WINSTON K.R. and WANG M.C.: Cranial bone fixation: Review of literature and description of a new procedure. J. Neurosurg., 99: 484-8, 2003.

6- KEEN W.W.: Surgery of the brain, spinal cord, and nerves, in Dercum FX (ed): A Text-Book on Nervous Diseases by American Authors. Philadelphia: Lea Brothers, pp. 957-1006, 1895.

7- KEEN W.W.: Three successful cases of cerebral surgery including (1) the removal of a large intracranial fibroma; (2) exsection of damaged brain tissue; and (3) exsection of the cerebral centre for the left hand; with remarks on the general technique of such operations. Trans. Am. Surg. Assoc, 6: 293-347, 1888.

8- LERCH K.D.: Reliability of cranial flap fixation techniques: Comparative experimental evaluation of suturing, titanium miniplates, and a new rivet-like titanium clamp 
(Skull fix): Technical note. Neurosurgery, 44: 902-5, 1999.

9- VÄLLFORS B. and FORSTER D.: An alternative method for the fixation of bone flaps after craniotomy. J. Neurosurg., 37: 620, 1972.

10- SPETZLER R.F.: Bone flap fixation: A new technique. Technical note. J. Neurosurg., 87: 475-6, 1997.

11- CHIBBARO S., MAKIESE O., MIRONE G., et al.: Skull bone flap fixation-comparative experimental study to assess the reliability of a new grip-like titanium device (Skull Grip) versus traditional sutures: Technical note. Minim. Invas. Neurosurg., 52: 98-100, 2009.

12- LEMCKE J., MEIER U. and AL-ZAIN F.: The clinical application of a new absorbable fixation clamp in craniotomy closure. A technical note after first experiences with 29 patients Acta Neurochir., 151: 1231-4, 2009.

13- VAN LOOCK K.1., MENOVSKY T., KAMERLING N., De RIDDER D.: Cranial bone flap fixation using a new device (Cranial LoopTM). Minim. Invasive Neurosurg., 54 (3): 119-24, 2011.

14- ESTIN D.1., TROFFKIN N. and HEILMAN C.B.: Bone flap fixation with titanium clamps: A new technique. Surg. Neurol., 53 (4): 391-4; discussion 394-5, 2000.

15-WAGNER W.: Die temporäre Resektion des Schädeldaches an Stelle der Trepanation. Centrabl. Chir., 16: 833-8, 1889.

16- WINSTON K.R. and WANG M.C.: Cranial bone fixation in infants and children. Pediatr. Neurosurg, 31: 225-30, 1999.
17- GONZALEZ E., ORTA J., QUERO C., et al.: Ethyl-2cyanoacrylate fixation of the cranial bone flap after craniotomy. Surg. Neurol., 53: 288-9, 2000.

18- IMOLA M.J. and SCHRAMM V.L.: Resorbable internal fixation in pediatric cranial base surgery. Laryngoscope, 112: 1897-901, 2002.

19- KURTZ S.M. and DEVINE J.N.: PEEK Biomaterials in trauma, orthopedic, and spinal implants. Biomaterials, 28: 4845-69, 2007

20- WÖRNER B.1., LANGE M., HERZOG A., FINK U. and OECKLER R.: A new method for surgical repair of impression fractures of the cranial vault and frontal sinus with rivet-like titanium clamps. Neurosurg. Rev. Jul., 24 (2-3): 83-7, 2001.

21- SCHILLINGER G., EBEL H., WALTER C., BROCKHAGEN H.C. and KLUG N.: Titanium clamps for refixation of bone fragments in the repair of depressed skull fractures. Zbl. Neurochir., 61 (1): 48, 2000.

22- ISAACS J.E., YEN SHIPLEY N., OWEN J.R., et al.: Biomechanical comparison of the holding strength of a peek-optima circular plate versus a stainless steel oblique T-plate for radioscapholunate arthrodesis. J. Hand. Surg. Am., 33: 1765-9, 2008.

23- SHELLOCK F.G. and SHELLOCK V.J.: Cranial bone flap fixation clamps: Compatibility at MR imaging. Radiology, 207: 822-5, 1998.

24- WONG L., DUFRESNE C.R., RICHTSMEIER J.T., et al.: The effect of rigid fixation on growth of the neurocranium. Plast. Reconstr. Surg., 93: 1-10, 1994. 


\section{تثبيت عظام الجمجمة مقارنة النتائج الإكلينيكية والإشعاعية مونية

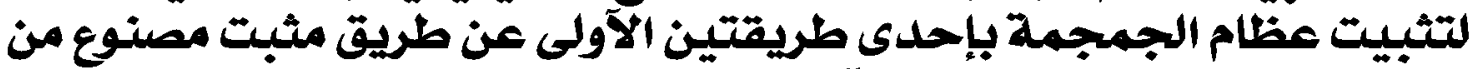 التيتانيوم والآخر من البولى إيثركيتون}

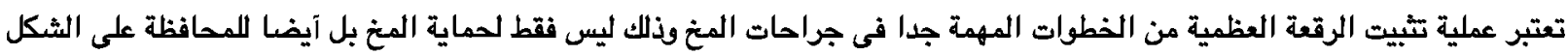
المظهرى والجمالى الجمجمة وتجنب المضاعفات مثل طفو آو إنخفاض الرقعة العظمية. وقد ظهرت مجموعة من التقنيات والمواد اللازمة لتشييت عظام الجمجمة على مدى العقود العديدة الماضية. الهدف من هذه الدراسة مقارنة النتائج الإكلينيكية والإشعاعية لتبيت عظام الجمجمة بإحدى طريقتين الآولى عن طريق مثبت مصنوع من التيتانيوم والآخر من البولى إيثر كيتون.

وقد تم إجراء هذه الدراسة الإسترجاعية عن طريق مراجعة الملفات الطبية وسجلات آربع وخمسين مريضا ممن آجرى لهم آلهم جراحات روتينية

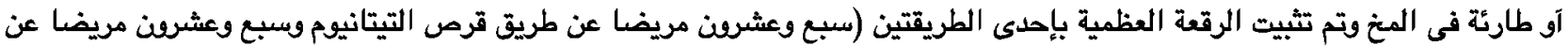

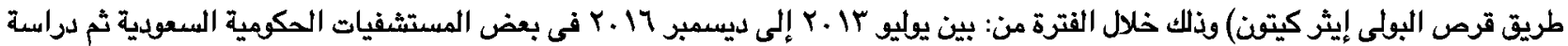

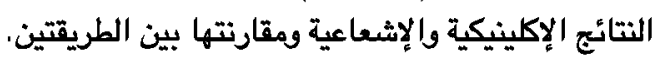

تم الحصول على نتائج مرضية فى كلا طريقتى التبيت وعند متابعة المرضى تبين حدوث تجمع خارج الآم الجافية فى آريع حالات وتحت

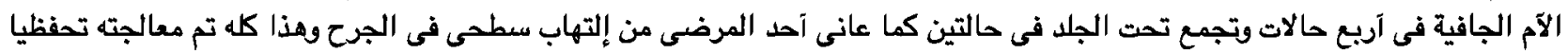

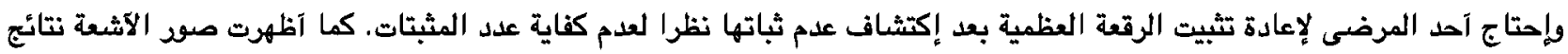

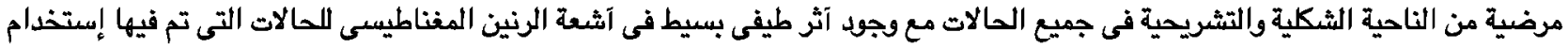
التيتانيوم وإنعدام ذلك الآثر فى الحالات التى تم فيها إستخدام البولى إيثر كيتفن.

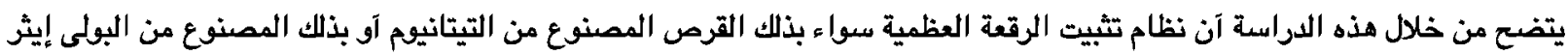

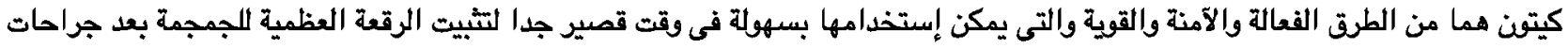

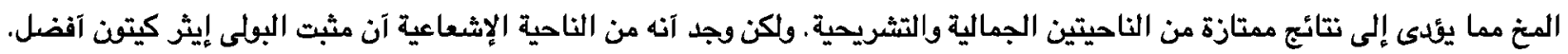

